\title{
Tampilan elongasi prosesus styloid pada pasien dengan gangguan sendi temporomandibula
}

\author{
Fitri Angraini Nasution', Azhari², Fahmi Oscandar ${ }^{2}$
}

\begin{abstract}
Objectives: The purpose of this case report was to report the finding of styloid process morphology in patients with TMD.

Case Report: A 22-years-old female patient came to the radiology installation of Rumah Sakit Gigi dan Mulut Unpad Bandung for a Cone Beam Computed Tomography - 3 Dimension (CBCT-3D) examination with a clinical diagnosis of temporomandibular joint disorders (TMD). CBCT-3D examination results showed a change in the shape and position of the right and left condyle head. The length of the styloid process from the sagittal view on the right side was $34,0 \mathrm{~mm}$ and the left side $35,0 \mathrm{~mm}$ with the elongation type styloid process according to

Langlais et al. on the right and the left sides were elongated (type I). The styloid process undergoes bilateral elongation with the same type of elongation between the right and the left sides. Angulation of the styloid process from the coronal view on the right side was $68,6^{\circ}$ and the left side $55,9^{\circ}$. There was a change in the shape of the right and left styloid processes from the axial view at the temporal base, middle and the tip of styloid process.

Conclusion: TMD provides an abnormality in elongation of styloid process, CBCT is an effective diagnostic imaging modalities in evaluation of styloid process length.

Keywords: Stylohyoid ligament, elongated styloid process, temporomandibular disorders

Cite this article: Nasution FA, Azhari, Oscandar F. Tampilan elongasi prosesus styloid pada pasien dengan gangguan sendi temporomandibula. Jurnal Radiologi Dentomaksilofasial Indonesia 2020;4(1)7-10. https://doi.org/10.32793/ jrdi.v4i1.474
\end{abstract}

\section{PENDAHULUAN}

Prosesus styloid adalah tulang lonjong, silindris, tipis, panjang dan tulang kartilago yang dimiliki oleh tulang temporal cranium. Posisi prosesus styloid berada anteromedial dari foramen stilomastoid, lateral dari foramen jugular dan kanalis karotid, yang memanjang ke arah medial, kaudal dan anterior. Medial dari prosesus styloid terdapat arteri karotid interna, vena jugularis interna dan saraf kranial IX, X, XI, XII. Apeks prosesus styloid adalah pada bagian lateral fossa tonsilar diantara arteri karotid interna dan arteri karotid eksterna. Saraf wajah berada pada anterior dan medial dari prosesus styloid. Saraf glosofaringeal berada dekat prosesus styloid setelah keluar dari foramen jugular. ${ }^{1}$

Kasus elongasi prosesus styloid rata-rata terjadi 2 hingga $4 \%$ dari seluruh populasi, hanya $4-10,3 \%$ yang memiliki tanda-tanda dan gejala klinis. ${ }^{1-3}$ Prevalensi kasus ini lebih sering terjadi pada perempuan dibandingkan laki-laki dengan perbandingan 3:1, meningkat sesuai pertambahan usia dan paling sering pada usia 50-59 tahun. ${ }^{2}$ Kasus bilateral paling sering tetapi tidak selalu disertai gejala bilateral dan tidak terdapat perbedaan yang signifikan antara sisi kiri dan kanan. ${ }^{4}$

Prosesus styloid terdiri dari dua bagian yaitu basal dan bagian yang diproyeksikan. Bagian basal pada orang dewasa tersembunyi oleh timpani sedangkan bagian yang diproyeksikan sebagai tempat perlekatan tiga otot dan dua ligamen. Otot stilofaringeus melekat di dekat dasar prosesus dari mesial dan sedikit ke posterior, otot stylohyoid dari posterior dan lateral medial dan otot styloglosus dari bagian depan dekat ujung prosesus styloid. ${ }^{5}$ Osifikasi prosesus styloid terjadi antara usia 5-8 tahun setelah kelahiran dan terus memanjang. Kecepatan pertumbuhan prosesus styloid akan semakin berkurang pada usia 30 tahun. $^{1}$

Prosesus styloid dan tulang hioid dihubungkan oleh ligamen stylohyoid. ${ }^{6}$ Ligamen stylohyoid berada pada ujung prosesus styloid yang mengarah ke inferior hingga lesser cornu tulang hioid. Kartilago embrionik dari ligamen stylohyoid berpotensi mengalami osifikasi sebagian atau seluruhnya pada orang dewasa. ${ }^{7}$ Ligamen stilomandibula merupakan ligamen aksesoris yang melekat pada otot tulang dan berada jauh dari TMJ yang bertindak pasif dalam mengendalikan gerakan mandibula. Ligamen stilomandibula dimulai dari prosesus styloid ke border posterior angulus mandibula dan bersatu dengan fasia otot pterigoid medial. Fungsi ligamen stilomandibula mirip dengan 

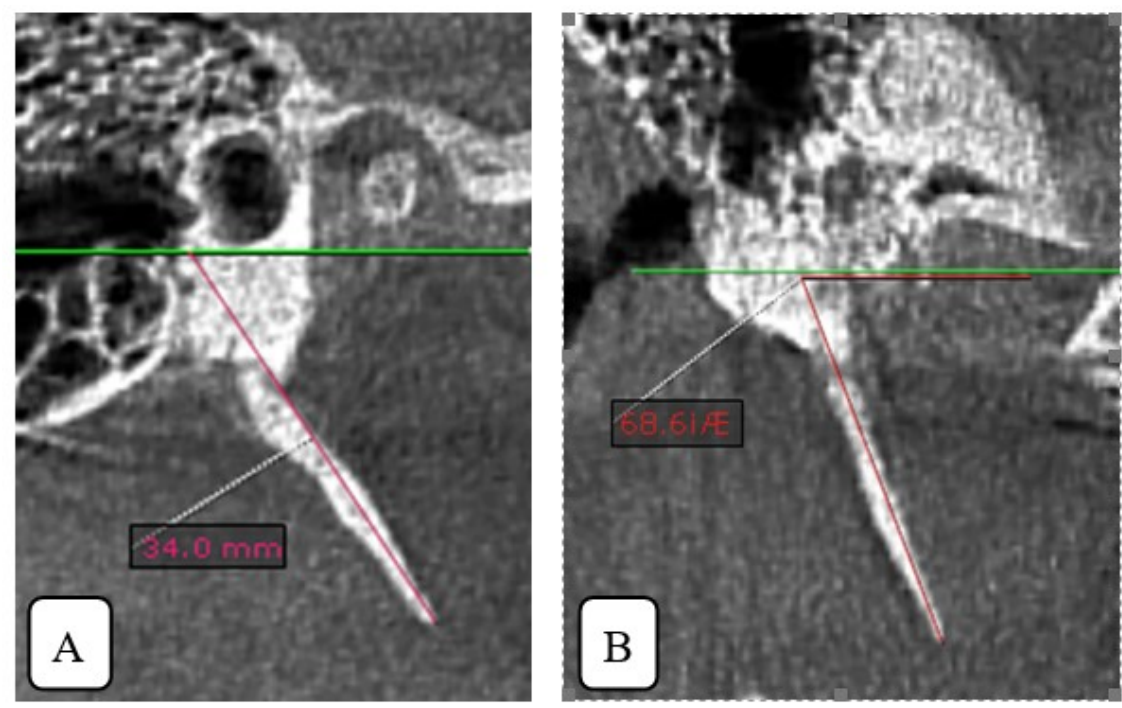

Gambar 1. Prosesus styloid sisi kanan. Gambaran sagital (A), panjang prosesus styloid dan gambaran koronal (B), angulasi prosesus styloid

ligamen sphenomandibula yaitu sebagai titik rotasi dan membatasi protrusif mandibula yang berlebihan. $^{8}$ Ligamen stilomandibula rileks bila mandibula menutup dan membuka lebar, meregang hanya pada gerakan protrusif ekstrim dan maksimal. Ligamen ini mengikat kuat rahang dan membantu pengaturan gerakan mandibula. ${ }^{9}$

Berdasarkan klasifikasi Langlais et al., terdapat tiga tipe bentuk elongasi prosesus styloid. Tipe I (elongated), elongasi terlihat lengkap tanpa ada struktur segmen. Tipe II (pseudosegmented) yaitu terdapat mineralisasi ligamen styloid yang melekat pada prosesus styloid oleh singlepseudoarticulation. Tipe III (segmented) mineralisasi ligamen terlihat terputus-putus menghasilkan gambaran multiple pseudoarticulation. $^{4}$

Laporan kasus ini melaporkan gambaran prosesus styloid pada seorang pasien perempuan berusia 22 tahun dengan diagnosis klinis TMD yang dilakukan pemeriksaan CBCT-3D. Gambaran prosesus styloid yang dilihat terdiri dari panjang, angulasi dan bentuk. Pengukuran panjang prosesus styloid adalah dari frankfurt horizontal plane (FHP) pada titik terendah kontur meatus akustikus eksternal ke ujung prosesus styloid pada gambaran sagital radiograf CBCT-3D menggunakan on demand $3 d$ dental software dengan skala numerik dan satuan $\mathrm{mm}$. Tipe elongasi prosesus styloid yaitu elongated, pseudosegmented atau segmented ditentukan dari gambaran sagital. Angulasi prosesus styloid adalah pengukuran sudut antara FHP bagian dasar tengkorak dan sumbu panjang prosesus styloid pada gambaran koronal radiograf CBCT-3D dengan skala numerik dan satuan derajat. Bentuk prosesus styloid ditentukan dari gambaran aksial radiograf CBCT-3D pada bagian dasar temporal, bagian tengah dan ujung prosesus styloid. Tujuan laporan kasus ini adalah melaporkan temuan bentuk prosesus styloid pada pasien dengan gangguan sendi temporomandibula (TMJ).

\section{LAPORAN KASUS}

Seorang perempuan berusia 22 tahun datang ke Instalasi Radiologi Rumah Sakit Gigi dan Mulut Unpad Bandung untuk dilakukan pemeriksaan CBCT 3D dengan diagnosis klinis TMD. Hasil pemeriksaan CBCT-3D terdapat perubahan bentuk dan posisi kepala kondilus kanan dan kiri. Panjang prosesus styloid dari gambaran sagital sisi kanan sekitar 34,0 $\mathrm{mm}$ (Gambar 1A) dan sisi kiri sekitar $35,0 \mathrm{~mm}$ (Gambar 3A). Tipe elongasi prosesus styloid menurut Langlais et al. pada sisi kanan dan kiri adalah elongated (tipe I). Pada pasien ini terjadi elongasi prosesus styloid bilateral dengan tipe elongasi yang sama antara sisi kanan dan kiri. Angulasi prosesus styloid sisi kanan dari gambaran koronal adalah sekitar $68,6^{\circ}$ (Gambar 1B), sisi kiri $55,9^{\circ}$ (Gambar 3B). Bentuk prosesus styloid sisi kanan dari gambaran aksial pada dasar temporal
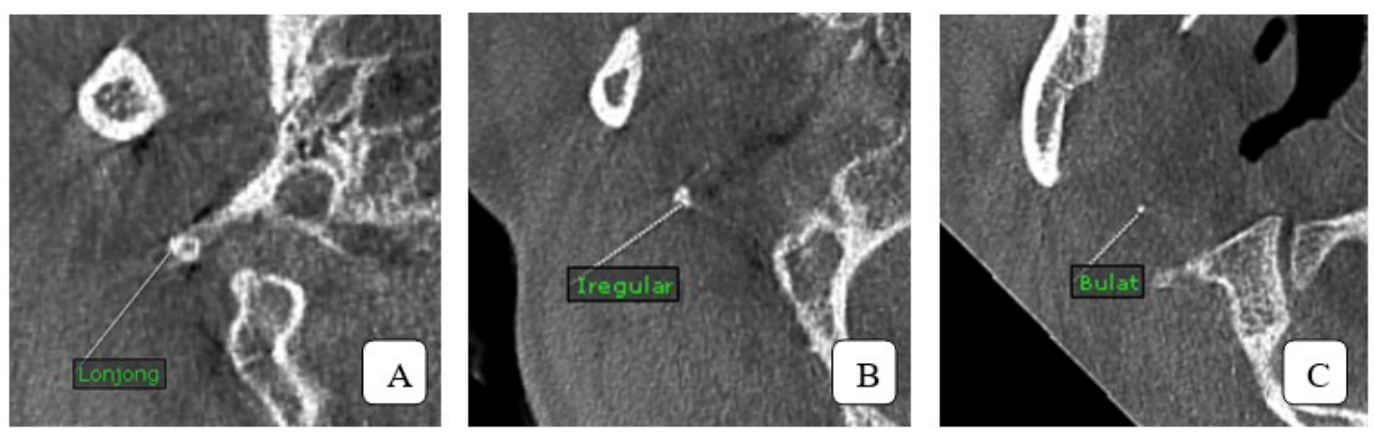

Gambar 2. Bentuk prosesus styloid sisi kanan pada bagian dasar (A), tengah (B) dan ujung (C) 

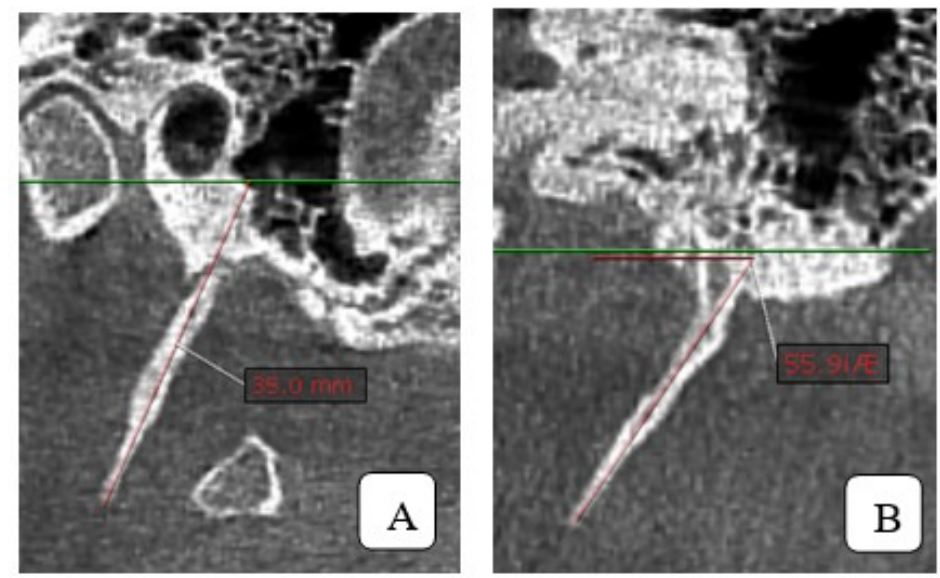

Gambar 3. Prosesus styloid sisi kiri. Gambaran sagittal (A), panjang prosesus styloid dan gambaran koronal (B), angulasi prosesus styloid
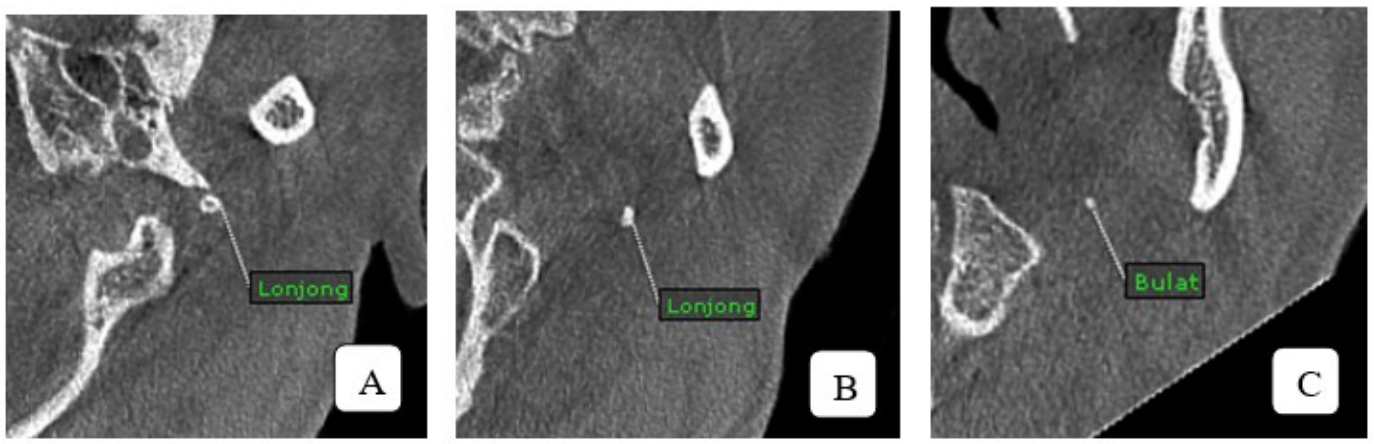

Gambar 4. Bentuk prosesus styloid sisi kiri pada bagian dasar (A), tengah (B) dan ujung (C)

adalah lonjong, bagian tengah iregular dan bagian ujung bulat (Gambar 2), sedangkan bentuk prosesus styloid sisi kiri pada dasar temporal adalah lonjong, bagian tengah lonjong dan bagian ujung bulat (Gambar 4).

\section{DISKUSI}

Lokasi prosesus styloid dari radiograf memanjang dari regio prosesus mastoid dan melewati posteroinferior ramus kearah tulang hioid. Posisi tulang hioid kurang lebih paralel atau superimposed dengan bagian posterior korteks inferior mandibula. Struktur internal prosesus styloid adalah radioopak homogen, tebal pada dasar prosesus, memanjang berbentuk runcing dan menipis kearah bawah. Osifikasi ligamen kurang lebih berbentuk lurus dan pada beberapa kasus terlihat berbentuk irregular pada permukaan luar. Osifikasi ligamen stylohyoid memanjang hingga tulang hioid dan disertai radiolusen penghubung sendi (pseudoartikulasi). ${ }^{10}$ Tipe I paling sering ditemukan pada kedua sisi pada penelitian Ilguy et al., Kursoglu et al. dan Donmez et al., tipe II paling sering ditemukan pada penelitian Oztunc et al. ${ }^{11}$

Prevalensi elongasi prosesus styloid atau mineralisasi ligamen stylohyoid yang dilaporkan sekitar 19,4 hingga 52,1\%, dan mengalami peningkatan $76 \%$ pada pasien TMD. ${ }^{12}$ Penelitian Guimaraes et al. pada 1.500 pasien TMD, 5,53\% terjadi perubahan morfologi prosesus styloid pada salah satu sisi TMJ, 56,6\% elongasi bilateral. Zaki et al. dan Krenmair et al. masing-masing menemukan perubahan morfologi prosesus styloid dengan prevalensi $27 \%$ dan $76 \%$ pada kasus TMD. Kasus elongasi ini lebih sering terjadi pada perempuan berdasarkan penelitian Guimaraes et al. dan Hernandez et al. Sedangkan menurut Gozil et al., Eagle dan Aral et al., prevalensi lebih tinggi pada laki-laki. ${ }^{13}$

Murtagh et al. mengemukakan tiga teori penyebab elongasi prosesus styloid. Teori pertama adalah elongasi kongenital yang disebabkan oleh persistensi prekursor kartilago, teori kedua adalah kalsifikasi ligamen stylohyoid karena proses yang tidak diketahui dan teori ketiga adalah jaringan tulang yang tumbuh pada area insersi ligamen stylohyoid. $^{14}$

Steinmann membagi teori osifikasi menjadi tiga yaitu theory reactive hyperplasia, theory of reactive metaplasia dan theory of anatomic variance. Theory reactive hyperplasia menyatakan bahwa trauma dapat menyebabkan osifikasi disepanjang ligamen stylohyoid. Theory of reactive metaplasia juga melibatkan respon penyembuhan post trauma yang menyimpang, adanya pusat osifikasi yang mengawali kalsifikasi ligamen. Gejala awal muncul dari ligamen yang kaku dengan keluhan adanya benda asing pada tenggorokan serta rasa sakit pada saat menelan. Theory of anatomic variance menyatakan bahwa elongasi prosesus styloid dan osifikasi ligamen stylohyoid adalah variasi anatomi yang terjadi tanpa adanya trauma. ${ }^{14-17}$

Camarda et al. mengemukakan istilah ligamen pseudostylohyoid, merupakan sindrom kalsifikasi yang tidak sebenarnya. Theory of aging developmental anomaly mengatakan bahwa proses 
penuaan berkaitan dengan hilangnya elastisitas jaringan lunak dan respon inflamasi lokal. Reaksi inflamasi ini menyebabkan inflamasi tendon pada pertemuan ligamen dan lesser cornu tulang hioid. ${ }^{6,14,18}$

Teori hipotesis genetik mengatakan bahwa kelainan anatomi dapat diturunkan secara genetik sebagai resesif autosom. ${ }^{18}$ Berdasarkan teori kongenital, tekanan mekanis selama masa intrauterin menyebabkan peregangan dari second branchial arch dan elongasi prosesus styloid. ${ }^{6}$

Hasil penelitian Oztunc et al. dari radiograf CBCT -3D pada 208 pasien memperlihatkan hasil $96(46 \%)$ normal, 28 (13\%) elongasi kiri, 16 (8\%) elongasi kanan dan 68 (33\%) bilateral. Pasien dengan elongasi terdapat penurunan sudut angulasi dan prevalensi gejala meningkat pada pasien dengan elongasi prosesus styloid. Pasien dengan rasa sakit wajah disertai elongasi rata-rata terdapat keluhan neurologik dibanding non elongasi. ${ }^{19}$ Langaroodi et al. melakukan penelitian pada 52 pasien dengan elongasi prosesus styloid simptomatik dan asimptomatik dari radiograf CBCT-3D. Hasil penelitian ditemukan bahwa tipe elongasi yang paling sering adalah segmented dan elongated. Morfologi dan ketebalan prosesus styloid berbeda signifikan antara simptomatik dan asimptomatik. ${ }^{20}$

\section{SIMPULAN}

Gangguan TMJ dapat memberikan kelainan berupa elongasi pada prosesus styloid, CBCT-3D adalah modalitas diagnostik yang efektif untuk evaluasi panjang prosesus styloid. Gambaran prosesus styloid bisa halus well-corticated atau padat dengan kontur irregular.

\section{DAFTAR PUSTAKA}

1. Baylan H. The anatomical basis of the symptoms of an elongated styloid process. J Hum Rythm. 2017;3(1):32-35

2. Haroun HS. Morphometric and radiological evaluation of the stylohyoid complex in man. Ann Int Med Den Res. 2015;1 (2):49-52.

3. Al-ekri L, Alsaei A. Incidental finding of an elongated styloid process during tonsillectomy procedure. Int J Otolaryngol Head Neck Surg. 2015;4(3):1-5.

4. Shah SP, Praveen N, Syed V, Subhashini A. Elongated styloid process: A retrospective panoramic radiographic study. World J Dent. 2012;3(4):316-319.

5. Verma S. Correlation of elongated styloid process with serum calcium levels. Int J Curr Res. 2016;8(4):29545-29550.

6. Vadgaonkar R, Murlimanju B, Prabhu L V, et al. Morphological study of styloid process of the temporal bone and its clinical implications. Anat Cell Biol. 2015;48(3):195-200.

7. Skrzat J, Mroz I, Walocha J, Zawilinski J, Jawarek J. Bilateral ossification of the stylohyoid ligament. Folia Morphol. 2007;66(3):203-206

8. GE G, PE L, PD W. Peterson's Principles of Oral and Maxillofacial Surgery.; 2004.

9. Cuccia AM, Caradonna C, Caradonna D. Manual therapy of the mandibular accessory ligaments for the management of temporomandibular joint disorders. J Am Osteopat Assoc. 2011;111(2):102-112.

10. White SC, Pharoah MJ. Oral Radiology Principles and Interpretation. 7th ed. St. Louis: Elsevier; 2014

11. Donmez M, Okumus O, Pekiner FN. Cone Beam Computed Tomographic evaluation of styloid process: A retrospective study of 1000 patients. Eur J Dent. 2017;11:210-215.

12. Taheri A, Firouzi-Marani S, Khoshbin M. Nonsurgical treatment of stylohyoid (Eagle) Syndrome: A case report. Korean Assoc Oral Maxillofac Surg. 2014;40(5):246-249.

13. Guimaraes SMR, Carvalho ACP, Guimaraes JP, Gomes MB, Cardoso $\mathrm{M}$ de MM, Reis HN. Prevalence of morphological alterations of the styloid process in patients with temporomandibular joint disorder. Radiol Bras. 2006;39 (6):407-411.

14. Hasan S. Eagles Syndrome: A current update. Acta Sci Dent Sci. 2018;2(5):49-52.

15. Fuentes R, Saravia D, Garay I, Ottone NE. Asymptomatic bilateral calcified stylohyoid ligaments detection by panoramic radiography and Cone Beam Computerized Tomography. Biomed Res-India. 2016;27(4):1-3.

16. Jakhar J, Khanagwal V, Aggarwal A, et al. Unilatera exceptionally elongated styloid process. I Punjab Acad Forensic Med Toxicol. 2010;10(2):107-110.

17. More CB, Asrani MK. Eagle's Syndrome: Report of three cases. Indian J Otolaryngol Head Neck Surg. 2011;63(4):396-399.

18. Mishra S, Krithika C, Sudarshan R, Selvamuthukumar $S$ Maheswari SU. Elongated styloid process - A review. J Pharm Biomed Sci. 2013;36(36):1871-1876.

19. Öztunç H, Evlice B, Tatli U, Evlice A. Cone-Beam Computed Tomographic evaluation of styloid process: A retrospective study of 208 patients with orofacial pain. Head Face Med. 2014;10(5):1-7

20. Langaroodi AJ, Zarch SHH, Rahpeyma A, Sanaei A. Assessment of stylohyoid ligament in patients with Eagle's Syndrome and patients with asymptomatic elongated styloid process: A Cone-Beam Computed Tomography study. J Oral Heal Oral Epidemiol. 2016;5(4):215-220. 